\title{
Animation of 3D Human Model Using Markerless Motion Capture Applied To Sports
}

\author{
Ashish Shingade ${ }^{1}$ and Archana Ghotkar ${ }^{2}$ \\ ${ }^{1,2}$ Department of Computer Engineering, Pune Institute of Computer Technology, \\ Pune, India
}

\begin{abstract}
Markerless motion capture is an active research in $3 D$ virtualization. In proposed work we presented a system for markerless motion capture for 3D human character animation, paper presents a survey on motion and skeleton tracking techniques which are developed or are under development. The paper proposed a method to transform the motion of a performer to a 3D human character (model), the 3D human character performs similar movements as that of a performer in real time. In the proposed work, human model data will be captured by Kinect camera, processed data will be applied on 3D human model for animation. 3D human model is created using open source software (MakeHuman). Anticipated dataset for sport activity is considered as input which can be applied to any HCI application.
\end{abstract}

\section{KEYWORDS}

Motion capture, Depth information, Rotation matrix, Animation

\section{INTRODUCTION}

Motion capture and computer animation techniques have made significant progress in game and film industry. Detecting movements of people in 3D and displaying it in a 3D virtual scene is a research problem.

There are two ways for motion capture, marker based motion capture and markerless motion capture. The Marker based motion capture has many drawbacks, the major drawback is that the performer has to wear a suit which consists of sensor or markers on it and the process consist of handling multiple cameras placed in a room, hence markerless motion capture has become a major area of research. In markerless motion capture the performer doesn't have to wear a suit, but still markerless motion capture is a challenging task.

The markerless motion capture is not an easy task to perform as it requires extra effort, so enough good results cannot be obtained using a single ordinary camera, the process still requires a set of multiples cameras placed all over the room, which also increases cost of the overall system. With the development of depth cameras such as Microsoft Kinect has eased the task of motion capture, without requiring the burden of multiple cameras, hence it decreases the cost of overall system.

This paper gives a survey on various available techniques related to motion capture. All these techniques intend to develop an automated body motion capture technique which helps to create a digital animation in 3D, which can ease the task of animators. This paper also presents a discussion on depth camera and libraries that can be applied for skeleton tracking. The paper proposes markerless motion capture system for 3D human character animation which can be 
applied for any HCI application like gaming, film industry, motion analysis in sports and many more.

For proposed idea kinect camera has been used, which captures real time videos and gives output as a skeleton. We apply kinect with Microsoft kinect SDK for better performance, for creating a human model open source software of Make Human [29] is used and rigging is performed using algorithm mentioned in [22].

The paper is organized as follows. Section II gives the review of motion and skeleton tracking techniques, section III gives discussion on depth cameras and libraries that can be applied for skeleton tracking, section IV presents the methodology, mathematical model in section $\mathrm{V}$ and conclusion is presented in section VI.

\section{RevieW OF Motion ANd SKeleton TraCking TECHNiQUES}

The researchers have surveyed various approaches for body motion and skeleton tracking for various applications. The body motion and skeleton tracking techniques using an ordinary camera are not easy and require extensive time in developing. The survey of motion capture and motion capture for animation using kinect is presented in Table 1. And the survey of body and skeleton tracking techniques are presented by the technique used along with advantages, disadvantages and illustration as shown in Table 2.

Table 1. Surveys of different motion capture techniques using kinect camera.

\begin{tabular}{|c|c|c|c|c|}
\hline Authors & Application & Pros and Cons & Illustrations & \\
\hline $\begin{array}{l}\text { Kairat Aitpayev, } \\
\text { Jaafar Gaber [1] }\end{array}$ & $\begin{array}{l}\text { Adding collision } \\
\text { object for human } \\
\text { body in augmented } \\
\text { reality using kinect }\end{array}$ & $\begin{array}{l}\text { 1. Easy to implement. } \\
\text { 2. System not accurate enough. } \\
\text { 3. Problems with measurement } \\
\text { of bones. }\end{array}$ & $\int_{11}^{2}$ & $\sqrt{11}$ \\
\hline $\begin{array}{l}\text { Xiaolong Tong, } \\
\text { Pin Xu, Xing Yan } \\
{[2]}\end{array}$ & $\begin{array}{l}\text { Skeleton animation } \\
\text { motion data based on } \\
\text { kinect }\end{array}$ & $\begin{array}{l}\text { 1. Creation of standard motion } \\
\text { data files in real time. } \\
\text { 2. Reduces funding of } \\
\text { implementation. } \\
\text { 3. Jitter present in data achieved } \\
\text { for foot. } \\
\text { 4. Lack in Optimization of } \\
\text { motion data. }\end{array}$ & & 14 \\
\hline $\begin{array}{l}\text { Ming Zeng, } \\
\text { Zhengcun Liu, } \\
\text { Qinghao Meng, } \\
\text { Zhengbiao Bai, } \\
\text { Haiyan Jia [3] }\end{array}$ & $\begin{array}{l}\text { Motion capture and } \\
\text { reconstruction based } \\
\text { on depth information } \\
\text { using kinect }\end{array}$ & $\begin{array}{l}\text { 1. Fairly accurate results } \\
\text { obtained for real time 3D human } \\
\text { body movements. } \\
\text { 2. Good fidelity and low latency } \\
\text { of system. } \\
\text { 3. No support for occlusion } \\
\text { handling. }\end{array}$ & & \\
\hline $\begin{array}{l}\text { Mian May, Feng } \\
\text { Xu, Yebin Liu [4] }\end{array}$ & $\begin{array}{l}\text { Animation of 3D } \\
\text { characters form } \\
\text { single depth camera }\end{array}$ & $\begin{array}{l}\text { 1. Noise and errors with joints } \\
\text { position are removed. } \\
\text { 2. Due to removal of noise good } \\
\text { results are obtained. } \\
\text { 3. The deformation models pose } \\
\text { is not that similar to the captured } \\
\text { character. } \\
\text { 4. Skinning is not done properly. }\end{array}$ & & \\
\hline
\end{tabular}




\begin{tabular}{|c|c|c|c|c|}
\hline $\begin{array}{l}\text { Charles E. Colvin, } \\
\text { Janie H. Babcock, } \\
\text { John H. Forrest, } \\
\text { Chase M. Stuart, } \\
\text { Matthew J. } \\
\text { Tonnemacher, and } \\
\text { Wen-Shin Wang } \\
\text { [5] }\end{array}$ & $\begin{array}{l}\text { Multiple user motion } \\
\text { capture and system } \\
\text { engineering }\end{array}$ & $\begin{array}{l}\text { 1. Support for mapping hand } \\
\text { gestures. } \\
\text { 2. Reduces funding of } \\
\text { implementation. } \\
\text { 3. Arm gestures not supported. }\end{array}$ & 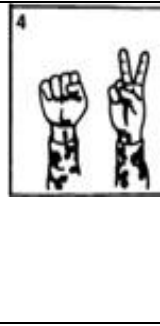 & हैं \\
\hline $\begin{array}{l}\text { Lucía Vera, Jesús } \\
\text { Gimeno, } \\
\text { Inmaculada Coma, } \\
\text { and Marcos } \\
\text { Fernández [6] }\end{array}$ & $\begin{array}{l}\text { Augmented Mirror: } \\
\text { Interactive } \\
\text { augmented reality } \\
\text { system based on } \\
\text { kinect }\end{array}$ & $\begin{array}{l}\text { 1. Head orientation, lip } \\
\text { movements, facial expressions } \\
\text { and automatic gestures (blink, } \\
\text { hands, feet, etc.) are handled. } \\
\text { 2. Occlusion is handled. } \\
\text { 3. Finger tracking not supported. } \\
\text { 4. Use of too many devices } \\
\text { makes system difficult to } \\
\text { implement. }\end{array}$ & & \\
\hline $\begin{array}{l}\text { Jing Tong, Jin } \\
\text { Zhou, Ligang Liu, } \\
\text { Zhigeng Pan, and } \\
\text { Hao Yan [17] }\end{array}$ & $\begin{array}{l}\text { Scanning 3D full } \\
\text { human bodies using } \\
\text { kinect }\end{array}$ & $\begin{array}{l}\text { 1. Inference phenomenon is } \\
\text { handled using multiple kinect. } \\
\text { 2. Complex occlusions are } \\
\text { handled. } \\
2 . \text { Reduces funding of } \\
\text { implementation. } \\
\text { 3. Algorithm is memory } \\
\text { efficient. } \\
\text { 4. The quality of the } \\
\text { reconstructed model is still poor. } \\
\text { 5. Misalignments are still } \\
\text { occurred } \\
\text { 6. Unnatural bending in arm } \\
\text { areas. }\end{array}$ & & \\
\hline $\begin{array}{l}\text { Chanjira } \\
\text { Sinthanayothin, } \\
\text { Nonlapas } \\
\text { Wongwaen, } \\
\text { Wisarut Bholsithi } \\
{[18]}\end{array}$ & $\begin{array}{l}\text { Skeleton tracking } \\
\text { using kinect sensor } \\
\text { and displaying in 3D } \\
\text { virtual scene }\end{array}$ & $\begin{array}{l}\text { 1. Bone joint movements are } \\
\text { detected in real time with correct } \\
\text { position tracking. } \\
\text { 2. No support for occlusion } \\
\text { handling. }\end{array}$ & & \\
\hline $\begin{array}{l}\text { Karina Hadad de } \\
\text { Souza, Rosilane } \\
\text { Ribeiro da Mota } \\
\text { [19] }\end{array}$ & $\begin{array}{l}\text { Motion Capture by } \\
\text { Kinect }\end{array}$ & $\begin{array}{l}\text { 1. Multiple kinect support for } \\
\text { motion capture. } \\
\text { 2. Increase in precision of } \\
\text { system. } \\
\text { 3. Occlusion handled with use of } \\
\text { multiple kinect. } \\
\text { 4. Not enough good } \\
\text { performance. } \\
\text { 5. With use of multiple kinect } \\
\text { data processing increase. }\end{array}$ & & is \\
\hline $\begin{array}{l}\text { Quanshi Zhang, } \\
\text { XuanSong, } \\
\text { Xiaowei Shao, } \\
\text { Ryosuke } \\
\text { Shibasaki, Huijing } \\
\text { Zhao [20] }\end{array}$ & $\begin{array}{l}\text { Unsupervised } \\
\text { Skeleton Extraction } \\
\text { and Motion Capture } \\
\text { from Kinect Video } \\
\text { via 3D Deformable } \\
\text { Matching }\end{array}$ & $\begin{array}{l}\text { 1. Approach is more robust than } \\
\text { the traditional video-based and } \\
\text { stereo-based approaches. } \\
\text { 2. Good performance is } \\
\text { obtained. } \\
\text { 3. No support for occlusion in } \\
\text { case when if a person folds his } \\
\text { hands together. }\end{array}$ & . & 52 \\
\hline
\end{tabular}




\begin{tabular}{l|l|l|}
\hline Hubert Shum, & Real-time Physical \\
Edmond S.L. Ho & $\begin{array}{l}\text { 1. Proposed algorithm is } \\
\text { computationally efficient and } \\
\text { Ch1] }\end{array}$ & $\begin{array}{l}\text { Can be applied to a wide variety } \\
\text { Movements with } \\
\text { of interactive virtual reality } \\
\text { applications }\end{array}$ \\
& $\begin{array}{l}\text { 2. No support for occlusions and } \\
\text { noises handling. }\end{array}$
\end{tabular}

Table 2. Survey of body and skeleton tracking techniques.

\begin{tabular}{|c|c|c|c|c|}
\hline Authors & Applications & Techniques & Pros and Cons & Illustrations \\
\hline $\begin{array}{l}\text { Adso } \\
\text { Fernandez- } \\
\text { Baena, } \\
\text { Antonio } \\
\text { Susin, Xavier } \\
\text { Lligadas [7] }\end{array}$ & $\begin{array}{l}\text { Biomechanica } \\
1 \text { validation of } \\
\text { upper-body } \\
\text { and lower- } \\
\text { body joint } \\
\text { movements of } \\
\text { kinect motion } \\
\text { capture data } \\
\text { for } \\
\text { rehabilitation } \\
\text { treatments }\end{array}$ & $\begin{array}{l}\text { Optical } \\
\text { Motion } \\
\text { Capture }\end{array}$ & $\begin{array}{l}\text { 1. Reduces funding of } \\
\text { implementation. } \\
\text { 2. Comparison of Kinect } \\
\text { motion capture with } \\
\text { optical motion capture. } \\
\text { 3. Fairly good results are } \\
\text { obtained. } \\
\text { 4. Lack of precision in } \\
\text { system. } \\
\text { 5. Approximation of } \\
\text { joints and bones not done } \\
\text { properly. }\end{array}$ & (4) \\
\hline $\begin{array}{l}\text { Jamie Shotton, } \\
\text { Andrew } \\
\text { Fitzgibbon, } \\
\text { Mat Cook, } \\
\text { Toby Sharp, } \\
\text { Mark } \\
\text { Finocchio, } \\
\text { Richard } \\
\text { Moore, Alex } \\
\text { Kipman, } \\
\text { Andrew Blake } \\
\text { [8] }\end{array}$ & $\begin{array}{l}\text { Real time } \\
\text { human pose } \\
\text { recognition in } \\
\text { parts from } \\
\text { single depth } \\
\text { camera }\end{array}$ & $\begin{array}{l}\text { Randomized } \\
\text { decision } \\
\text { forests }\end{array}$ & $\begin{array}{l}\text { 1. Quickly and accurately } \\
\text { predicts 3D positions of } \\
\text { body joints from single } \\
\text { depth image, using no } \\
\text { temporal information. } \\
\text { 2. Ability to run the } \\
\text { classifier in parallel on } \\
\text { each pixel on a GPU to } \\
\text { increase the speed. } \\
\text { 3. Using large and highly } \\
\text { varied training dataset to } \\
\text { estimate body parts } \\
\text { invariant to pose, body } \\
\text { shape, clothing, etc. to } \\
\text { pose the relation between } \\
\text { two adjacent parts. }\end{array}$ & \\
\hline $\begin{array}{l}\text { Wei Qu, Dan } \\
\text { Schonfeld [9] }\end{array}$ & $\begin{array}{l}\text { Real-time } \\
\text { decentralized } \\
\text { articulated } \\
\text { motion } \\
\text { analysis and } \\
\text { object } \\
\text { tracking from } \\
\text { videos }\end{array}$ & $\begin{array}{l}\text { Decentralized } \\
\text { articulated } \\
\text { object tracking } \\
\text { (DAOT), } \\
\text { hierarchical } \\
\text { articulated } \\
\text { object tracking } \\
\text { (HAOT). }\end{array}$ & $\begin{array}{l}\text { 1. Fast and easy to } \\
\text { implement. } \\
2 . \text { Results not shown in } \\
\text { case of self-occlusion due } \\
\text { to the fact that it cannot } \\
\text { handle pose relation } \\
\text { between two adjacent } \\
\text { parts. }\end{array}$ & \\
\hline $\begin{array}{l}\text { Jesus } \\
\text { Martınez del } \\
\text { Rincon, } \\
\text { Dimitrios } \\
\text { Makris, Carlos } \\
\text { Orrite, Jean- } \\
\text { Christophe } \\
\text { Nebel [10] }\end{array}$ & $\begin{array}{l}\text { Tracking } \\
\text { human } \\
\text { position and } \\
\text { lower body } \\
\text { parts using } \\
\text { Kalman and } \\
\text { particle filters } \\
\text { constrained by } \\
\text { human }\end{array}$ & $\begin{array}{l}\text { Position } \\
\text { Tracking } \\
\text { Based on a } \\
\text { Kalman Filter, } \\
\text { multiple- } \\
\text { Particle-Filter } \\
\text { Tracking } \\
\text { Based on Two- } \\
\text { Dimensional } \\
\end{array}$ & $\begin{array}{l}\text { 1. Bipedal motion is } \\
\text { handled without any } \\
\text { constraints. } \\
\text { 2. Occlusion is seen case } \\
\text { of pivot joints. }\end{array}$ & \\
\hline
\end{tabular}


International Journal of Computer Graphics \& Animation (IJCGA) Vol.4, No.1, January 2014

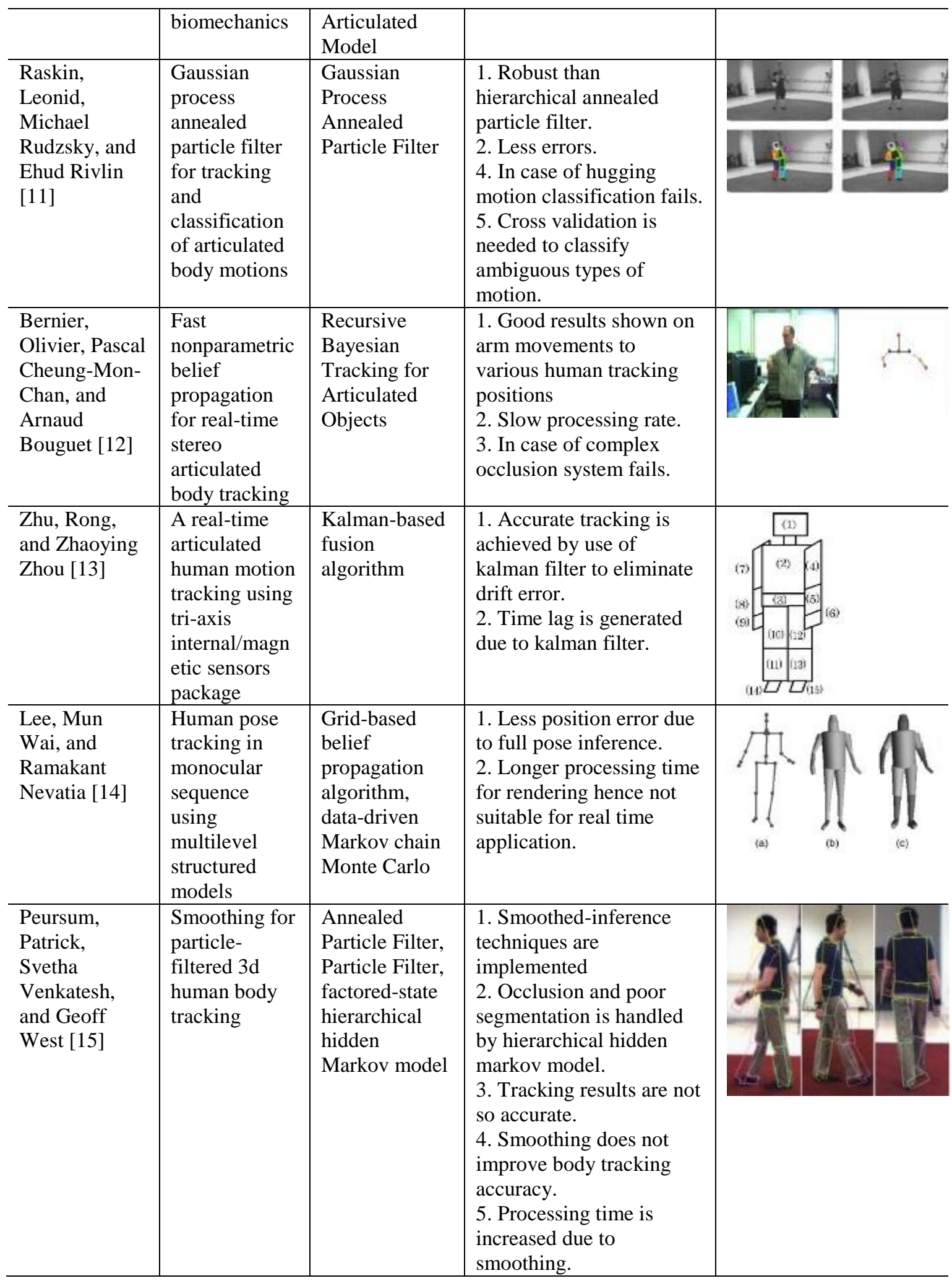


International Journal of Computer Graphics \& Animation (IJCGA) Vol.4, No.1, January 2014

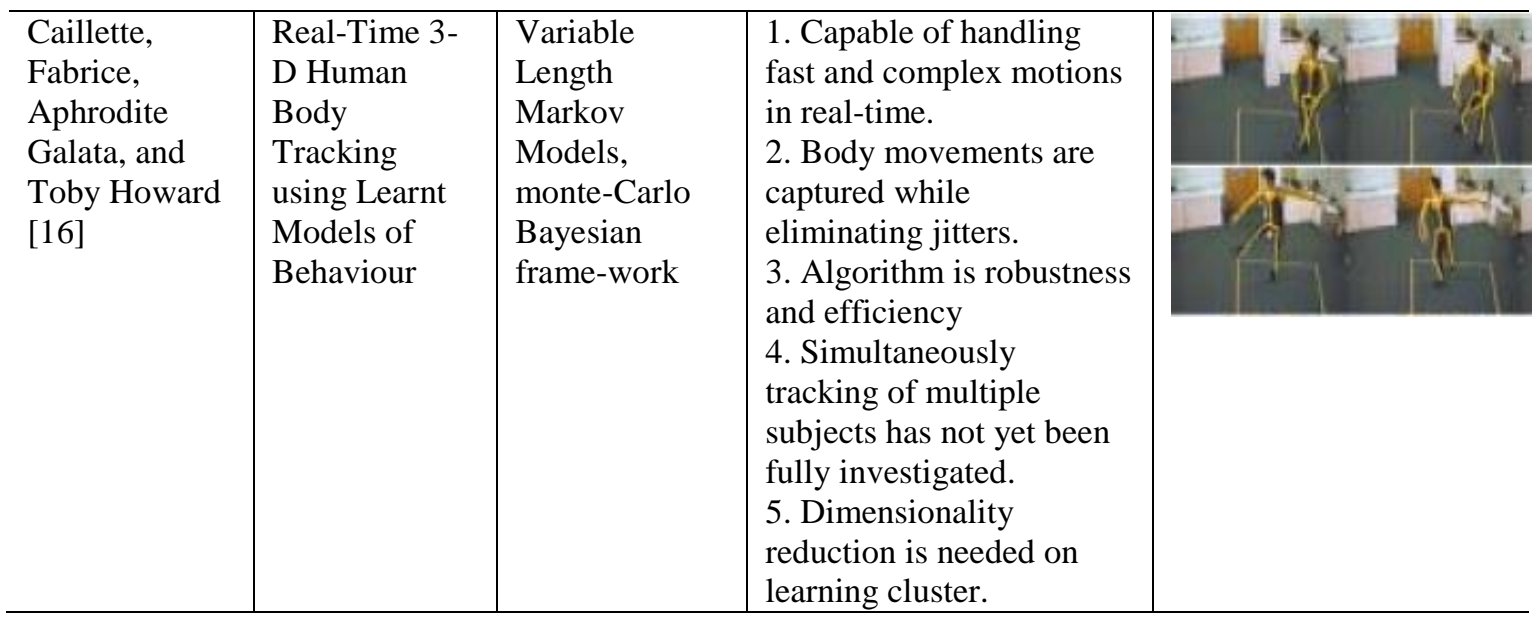

\section{REVIEW OF DEPTH CAMERAS AND LIBRARIES SUPPORTED}

In Table 3 presents a survey on depth cameras available in market with their specifications, and Table 4 gives a comparison of different Natural User Interface (NUI) libraries available with advantages and disadvantages.

Table 3. Survey of different depth cameras with their specifications.

\begin{tabular}{l|l|l|l|l}
\hline Specifications & Kinect Camera & $\begin{array}{l}\text { Sony PlayStation } \\
\text { Eye }\end{array}$ & $\begin{array}{l}\text { Prime Sense } \\
\text { Sensor }\end{array}$ & $\begin{array}{l}\text { Intel's Creative } \\
\text { Camera }\end{array}$ \\
\hline Illustration & &
\end{tabular}


International Journal of Computer Graphics \& Animation (IJCGA) Vol.4, No.1, January 2014

\begin{tabular}{|c|c|c|c|c|}
\hline Comments & $\begin{array}{l}\text { 1. Widely used for } \\
\text { gaming and } \\
\text { application } \\
\text { development. } \\
\text { 2. Fastest selling } \\
\text { electronic device. } \\
\text { 3. Drivers are made } \\
\text { available from } \\
\text { Microsoft as well as } \\
\text { third party drivers } \\
\text { are also available. }\end{array}$ & $\begin{array}{l}\text { 1. Drivers are not } \\
\text { still available from } \\
\text { Sony. } \\
\text { 2. PlayStation } \\
\text { playing experience } \\
\text { is enhanced. }\end{array}$ & $\begin{array}{l}\text { 1. Best depth } \\
\text { performance. } \\
\text { 2. Low-power } \\
\text { consumption. } \\
\text { 3. OpenNI } \\
\text { compatible. }\end{array}$ & $\begin{array}{l}\text { 1. Very limited } \\
\text { device range. } \\
\text { 2. Portable } \\
\text { camera with HD } \\
\text { support. } \\
\text { 3. Drivers are } \\
\text { made available } \\
\text { from Intel. }\end{array}$ \\
\hline
\end{tabular}

Table 4. A comparison table for Natural User Interface (NUI) libraries.

\begin{tabular}{|c|c|c|c|}
\hline \# & Techniques & Pros & Cons \\
\hline 1 & $\begin{array}{l}\text { Microsoft } \\
\text { Kinect SDK }\end{array}$ & $\begin{array}{l}\text { 1. Easy to install, fairly widespread. } \\
\text { 2. New version support skeleton tracking. } \\
\text { 3. Does not require camera calibration. } \\
\text { 4. Able to grab the full } 1280 \times 960 \\
\text { resolution of the camera. } \\
\text { 5. Predictive tracking of joints. } \\
\text { 6. Skeleton Recognition is done very fast. } \\
\text { 7. Joints occlusion handled. } \\
\text { 8. Description of the SDK architecture and } \\
\text { documentation for the APIs. }\end{array}$ & $\begin{array}{l}\text { 1. Support for windows only. } \\
\text { 2. No skeleton tracking. } \\
\text { 3. Limited language support, only for } \\
\text { C/C++ and C\#. } \\
\text { 4. Higher processing power. }\end{array}$ \\
\hline 2 & OpenNI/NITE & $\begin{array}{l}\text { 1. Very popular, and ready to use methods. } \\
\text { 2. Support skeleton tracking. } \\
\text { 3. Available for most languages. } \\
\text { 4. Any OS compatible. }\end{array}$ & $\begin{array}{l}\text { 1. Difficult to install. } \\
\text { 2. Calibration pose is required. } \\
\text { 3. OpenNI is limited to } 800 \times 600 \\
\text { resolution. } \\
\text { 4. No predictive tracking. } \\
\text { 5. Joints occlusion not handled } \\
\text { properly. } \\
\text { 6. Gets confused with very fast } \\
\text { movements. }\end{array}$ \\
\hline 3 & Libfreenect & $\begin{array}{l}\text { 1. Support for several applications. } \\
\text { 2. Any OS compatible. } \\
\text { 3. Available for most languages. }\end{array}$ & $\begin{array}{l}\text { 1. Difficult to install. } \\
\text { 2. No skeleton tracking. }\end{array}$ \\
\hline 4 & CL NUI & $\begin{array}{l}\text { 1. Can capture wide range of body } \\
\text { movements. } \\
\text { 2. Camera noise can be filtered. }\end{array}$ & $\begin{array}{l}\text { 1. Cannot perform motion } \\
\text { prediction. } \\
\text { 2. No support for occlusion handling. }\end{array}$ \\
\hline 5 & Evoluce SDK & $\begin{array}{l}\text { 1. Support various gesture recognition } \\
\text { methods. } \\
\text { 2. Easy to install. } \\
\text { 3. Support skeleton tracking. }\end{array}$ & $\begin{array}{l}\text { 1. Only for Windows } 7 \text {. } \\
\text { 2. Calibration pose is required. } \\
\text { 3. Limited language support, only for } \\
\mathrm{C} / \mathrm{C}++ \text { and } \mathrm{C} \# \text {. }\end{array}$ \\
\hline 6 & $\begin{array}{l}\text { Delicode } \\
\text { NImate }\end{array}$ & $\begin{array}{l}\text { 1. Quite fast. } \\
\text { 2. Support skeleton tracking. } \\
\text { 3. Does not require camera calibration. }\end{array}$ & $\begin{array}{l}\text { 1. Skeleton tracking not done } \\
\text { properly. } \\
\text { 2. Only for Windows. }\end{array}$ \\
\hline
\end{tabular}

\section{Methodology}

From the above survey, it has been observed that detecting skeleton joints and tracking is a major problem. So kinect camera is a better option to get depth information of human body which is used in the proposed system. 
Some researchers have tried to use more than one camera to detect and determine the depth of an object, which increases the cost and the system slows down due to increased data processing. Fortunately, due to the advancement in camera technology, depth camera such as kinect sensor makes it possible to get the depth of an object.

As using the depth information provided by kinect camera, each pixel corresponds to the estimate of the distance between the kinect camera and the closest object in the scene at that pixel's location, with the help of this information kinect camera allows to track different parts of human body in three dimension.

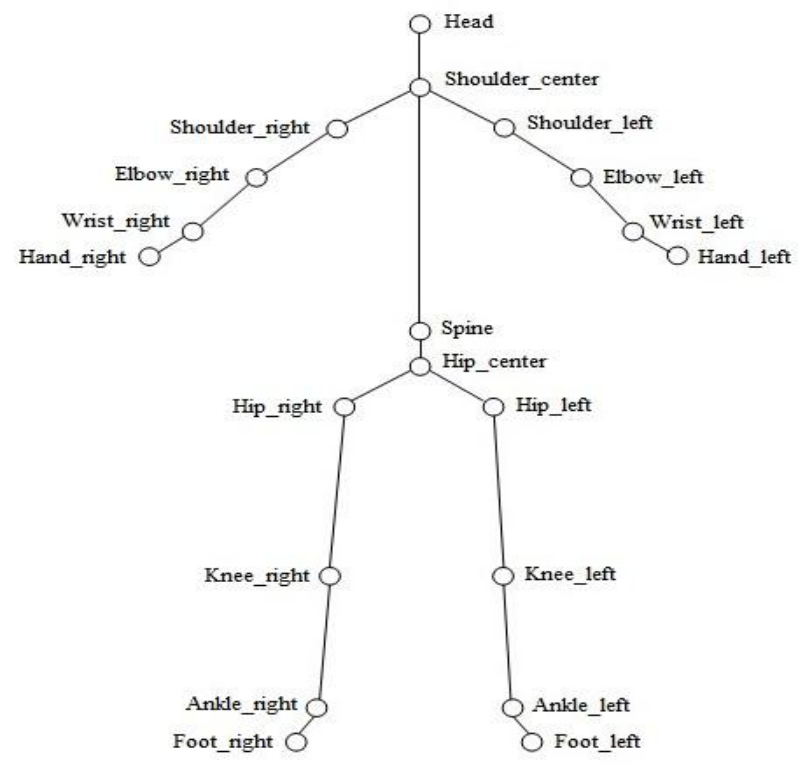

Figure 1. Kinect skeleton model of joints

Kinect camera allows us to produce depth, texture, user and skeleton information. The depth information is obtained from IR cameras on kinect; the texture information is the RGB color map of the scene which can be obtained through the RGB camera on the kinect. The user information is obtained from the binary images which includes the detected people in the scene. To obtain the skeleton information the person has to stand in front of kinect camera, as we are using MS kinect SDK calibration pose is not required and kinect tracks the human skeleton in real time. The MS kinect SDK is a middle ware framework supported by kinect camera; we get 20 joint positions using MS kinect SDK. The skeleton joint positions obtained from kinect camera are shown in figure 1. Following are the major steps involved in the proposed system.

Steps:

1. Skeleton Recognition and Tracking

2. 3D Human Model Creation

3. Rigging

4. Application of Motion Data to Rig

The Table 5 shows the dataset defined for the system to apply for sports; the gestures involved are recognised by the kinect camera. The following figure 2 shows the proposed methodology of our system, the system consist of the following major phases in implementation. 
International Journal of Computer Graphics \& Animation (IJCGA) Vol.4, No.1, January 2014

Table 5. Anticipated dataset applied to sports.

\begin{tabular}{l|l|l|l}
\hline$\#$ & Gestures & Joints Involved & Additional Information \\
\hline 1 & Sprinting & Hip, Knee, Ankle & Short running \\
\hline 2 & Jumping & Hip, Knee, Ankle & $\begin{array}{l}\text { Distance from ground to } \\
\text { jumped object }\end{array}$ \\
\hline 3 & 1 Hand wave & Hand, Wrist, Elbow, Shoulder & Left/Right hand wave \\
\hline 4 & 2 Hands wave & Hand, Wrist, Elbow, Shoulder & Both hands wave \\
\hline 5 & Throwing & Shoulder, Elbow, Wrist & Throwing a ball \\
\hline 6 & Heading & Head, Shoulder & Heading a ball \\
\hline 7 & Kicking & Hip, Knee, Ankle & Kicking a ball \\
\hline
\end{tabular}

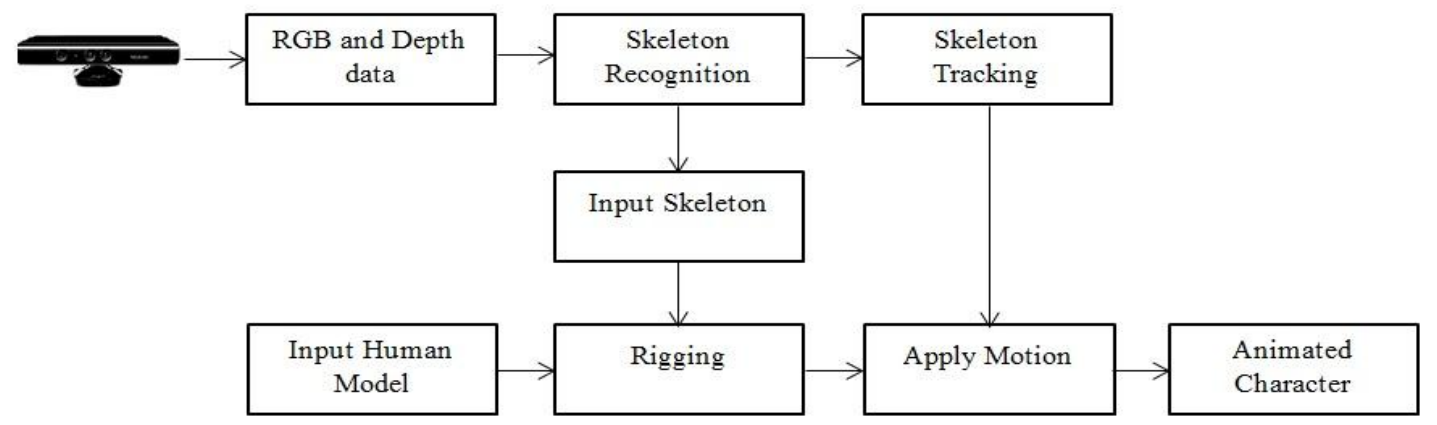

Figure 2. System block diagram

\subsection{Skeleton Recognition and Tracking}

The process of extracting skeleton of the body from the input data is termed as skeleton recognition and capturing the movements of each joint position frame by frame is termed as skeleton tracking.

The skeleton recognition is done using Kinect camera, the process includes separating foreground from background; once the foreground is obtained, human body is separated out and the human body is segmented into different regions to get the skeleton joints. This technique is done using the algorithm based on the paper by Shotton and et. al. [8]. The skeleton tracking is done using MS Kinect SDK framework.

\subsection{D Human Model Creation}

The 3D human model is created using open source software of MakeHuman and student version of Autodesk Maya. The process consists of following phases.

1. Mesh model is created.

2. Texture is applied on the mesh.

3. Clothing is applied on the human model.

\subsection{Rigging}

Rigging is the process of attaching skeleton to a human model; the human model is prepared using open source software of Make Human. The joints of the skeleton need to be placed at corresponding positions on the created human model in order to map rig character skeleton with captured kinect skeleton. 
The input to rigging phase is the human model created and the input skeleton obtained from the kinect camera, to perform the rigging process we use the algorithm based on the paper by Ilya Baran and Jovan Popovic [22]. The output of the rigging phase is skeleton attached to the human model.

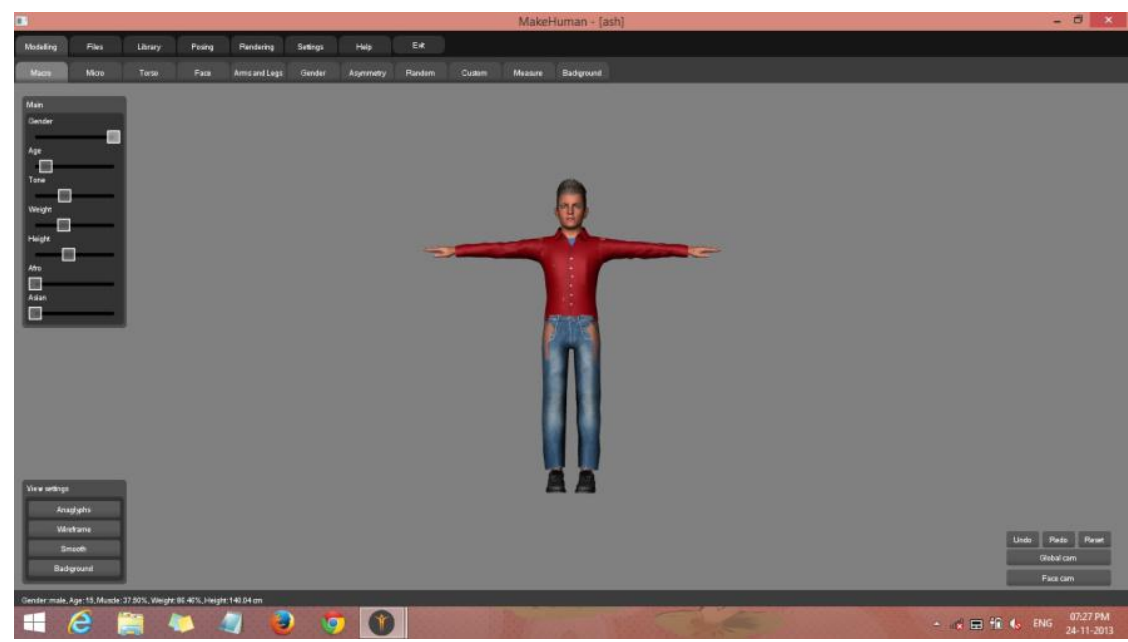

Figure 3. 3D human model created using MakeHuman.

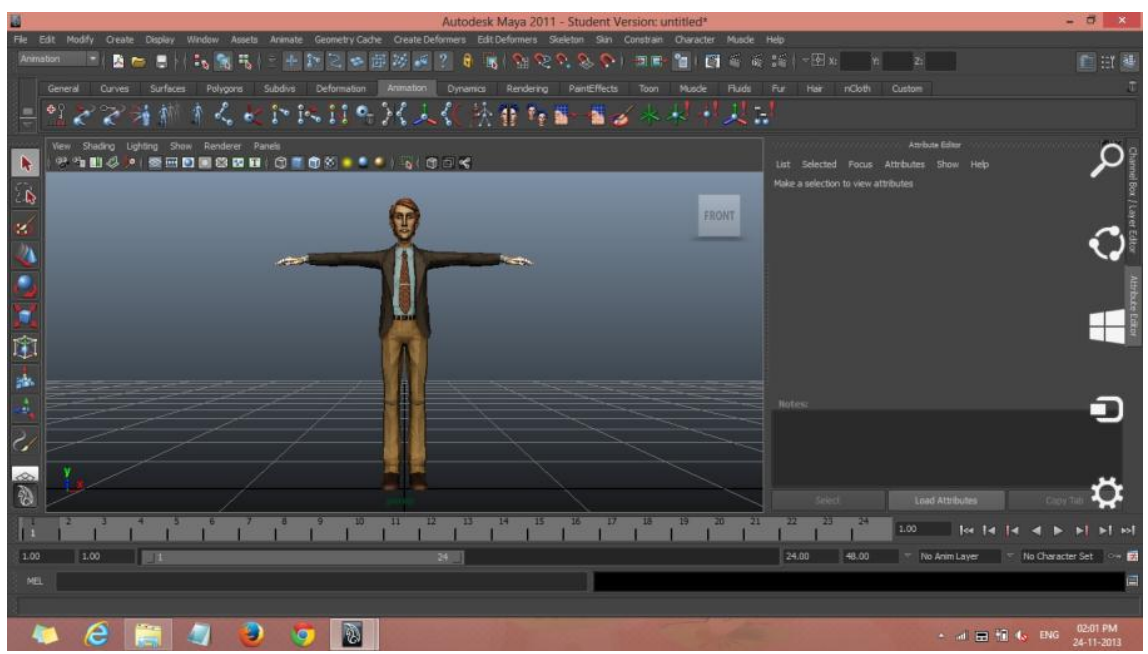

Figure 4. 3D human model created using Autodesk Maya.

\subsection{Application of Motion Data to Rig}

Once the rigging process is completed we need to apply the motion data that we get from skeleton tracking phase to rig character to perform animation. The data obtained from skeleton tracking phase is relevant only to the position of joints. Making the rig character to follow these positions is not correct; due to mismatch of size. Hence we need to extract rotations obtained from skeleton tracking phase to the rig character, to do so we use the concept of motion data transformation using rotation matrix.

To compute the rotation matrix, we need to get the rotation angles of all the joints relatively to $\mathrm{x}$, $\mathrm{y}$ and $\mathrm{z}$ axis. But we have only the joints positions in every frame. In order to compute all joints rotation matrix $\mathrm{A}$ satisfying equation $\mathrm{Y}=\mathrm{AX}$, where $\mathrm{Y}, \mathrm{X}$ are the transformed and original vertices respectively and $A$ is the rotation matrix. To compute the original rotation matrix $M(v$, 
$\theta)$ through the following equation using a unit vector $\mathrm{v}=(\mathrm{x}, \mathrm{y}, \mathrm{z})$ which is perpendicular to $\mathrm{a}, \mathrm{b}$. Where $a$ is vector of one bone of the last frame and $b$ is vector of same bone in current frame.

$$
\mathrm{M}(\mathrm{v}, \theta)=\left[\begin{array}{ccc}
\cos \theta+(1-\cos \theta) x^{2} & (1-\cos \theta) x y-(\sin \theta) z & (1-\cos \theta) x z+(\sin \theta) y \\
(1-\cos \theta) y x+(\sin \theta) z & \cos \theta+(1-\cos \theta) y^{2} & (1-\cos \theta) y z-(\sin \theta) x \\
(1-\cos \theta) z x-(\sin \theta) y & (1-\cos \theta) z y+(\sin \theta) x & \cos \theta+(1-\cos \theta) z^{2}
\end{array}\right]
$$

The final rotation matrix is computed as:

$$
\mathrm{R}(\mathrm{j})=\prod_{i=1}^{n} M(v, \theta)
$$

Once the rotations are transformed to the rig character, the rig character performs similar actions as that of the performer, which will be the output of the system.

\section{MAThematical Model}

The mathematical model for the proposed system is stated below.

Objective: Real time 3D character animation using markerless motion capture.

Let $\mathrm{S}$ be the system, such that

$\mathrm{S}=\{\mathrm{I}, \mathrm{O}, \mathrm{F}, \mathrm{Su}, \mathrm{Fa}\}$

$\mathrm{I}=$ Input to the system

$\mathrm{O}=$ Output of the system

$\mathrm{F}=$ Set of functions

$\mathrm{Su}=$ Success

$\mathrm{Fa}=$ Failure

1. Input

$$
\mathrm{I}=\{\mathrm{R}, \mathrm{D}\}
$$

$\mathrm{R}=\{\mathrm{r} 1, \mathrm{r} 2, \mathrm{r} 3 \ldots \mathrm{rn}\}$ - set of RGB image frames.

2. Output

$D=\{d 1, d 2, d 3 \ldots . d n\}-$ set of depth image frames.

3. Functions

$\mathrm{O}=\{$ animated character which performs same action as that of the performer $\}$.

$$
\begin{aligned}
& F=\{S R, S T, R I, A M\} \\
& S R-\text { Skeleton recognition } \\
& S R=\{j 1, j 2, j 3 \ldots . . j 20\}-\text { set of skeleton joints. } \\
& S T-\text { Skeleton tracking }
\end{aligned}
$$

Let $\mathrm{Y}$ be the Transformed matrix such that

$\mathrm{Y}=\mathrm{AX}$

Where $\mathrm{Y}, \mathrm{X}$ are the transformed and original vertices respectively and $\mathrm{A}$ is the rotation matrix.

Assumptions:

1. Assume the motion of character is coherent.

2. The current rotation of each joint is an addition of the rotations before.

Based on above assumptions we compute the rotation matrix $M(v, \theta)$, as shown in equation (1) using a single rotation angle $\theta$ and a unit vector $\mathrm{v}=(\mathrm{x}, \mathrm{y}, \mathrm{z})$ which is perpendicular to $\mathrm{a}, \mathrm{b}$.

The final rotation matrix is computed as shown in equation (2).

4. Success

$\mathrm{Su}=\{$ character performs similar action as that of the performer $\}$. 
5. Failure

$\mathrm{Fa}=\{1$. Character does not perform any action

2. Character performs dissimilar action $\}$.

\section{Conclusions}

After conducting a survey on different motion capture and skeleton tracking technique, it is found that there is lot of scope for the development of such system. Hence, we proposed a system using markerless motion capture for 3D human character animation using kinect camera, which takes comparatively less development and processing time, this technique can widely be applied for gaming and film industry.

We have also done survey on various depth cameras available and different NUI libraries available for development with these cameras.

\section{REFERENCES}

[1] Aitpayev, K.; Gaber, J., "Collision Avatar (CA): Adding collision objects for human body in augmented reality using Kinect," Application of Information and Communication Technologies (AICT), 2012 6th International Conference on, vol., no., pp.1,4, 17-19 Oct. 2012.

[2] Xiaolong Tong; Pin Xu; Xing Yan, "Research on Skeleton Animation Motion Data Based on Kinect," Computational Intelligence and Design (ISCID), 2012 Fifth International Symposium on , vol.2, no., pp.347,350, 28-29 Oct. 2012.

[3] Ming Zeng; Zhengcun Liu; Qinghao Meng; Zhengbiao Bai; Haiyan Jia, "Motion capture and reconstruction based on depth information using Kinect," Image and Signal Processing (CISP), 2012 5th International Congress on , vol., no., pp.1381,1385, 16-18 Oct. 2012.

[4] Mian Ma; Feng Xu; Yebin Liu, "Animation of 3D characters from single depth camera," 3D Imaging (IC3D), 2011 International Conference on, vol., no., pp.1,4, 7-8 Dec. 2011.

[5] Colvin, C.E.; Babcock, J.H.; Forrest, J.H.; Stuart, C.M.; Tonnemacher, M.J.; Wen-Shin Wang, "Multiple user motion capture and systems engineering," Systems and Information Engineering Design Symposium (SIEDS), 2011 IEEE , vol., no., pp.137,140, 29-29 April 2011.

[6] Vera, Lucía, et al. "Augmented mirror: interactive augmented reality system based on kinect." Human-Computer Interaction-INTERACT 2011. Springer Berlin Heidelberg, 483-486. 2011.

[7] Fern'ndez-Baena, Adso, Antonio Susin, and Xavier Lligadas. "Biomechanical validation of upperbody and lower-body joint movements of kinect motion capture data for rehabilitation treatments." Intelligent Networking and Collaborative Systems (INCoS), 2012 4th International Conference on. IEEE, 2012.

[8] J. Shotton, A. Fitzgibbon, M. Cook, T. Sharp, M. Finocchio, R. Moore, A. Kipman, and A. Blake. Real-time human pose recognition in parts from single depth images. In Computer Vision and Pattern Recognition (CVPR), 2011 IEEE Conference on, pages 1297 -1304, june 2011.

[9] Qu, Wei, and Dan Schonfeld. "Real-time decentralized articulated motion analysis and object tracking from videos." Image Processing, IEEE Transactions on 16.8 (2007): 2129-2138.

[10] del Rincón, Jesús Martínez, et al. "Tracking human position and lower body parts using Kalman and particle filters constrained by human biomechanics." Systems, Man, and Cybernetics, Part B: Cybernetics, IEEE Transactions on 41.1 (2011): 26-37. 
International Journal of Computer Graphics \& Animation (IJCGA) Vol.4, No.1, January 2014

[11] Raskin, Leonid, Michael Rudzsky, and Ehud Rivlin. "Dimensionality reduction using a Gaussian Process Annealed Particle Filter for tracking and classification of articulated body motions." Computer Vision and Image Understanding 115.4 (2011): 503-519.

[12] Bernier, Olivier, Pascal Cheung-Mon-Chan, and Arnaud Bouguet. "Fast nonparametric belief propagation for real-time stereo articulated body tracking." Computer Vision and Image Understanding 113.1 (2009): 29-47.

[13] Zhu, Rong, and Zhaoying Zhou. "A real-time articulated human motion tracking using tri-axis inertial/magnetic sensors package." Neural Systems and Rehabilitation Engineering, IEEE Transactions on 12.2 (2004): 295-302.

[14] Lee, Mun Wai, and Ramakant Nevatia. "Human pose tracking in monocular sequence using multilevel structured models." Pattern Analysis and Machine Intelligence, IEEE Transactions on 31.1 (2009): 27-38.

[15] Peursum, Patrick, Svetha Venkatesh, and Geoff West. "A study on smoothing for particle-filtered 3d human body tracking." International Journal of Computer Vision 87.1-2 (2010): 53-74.

[16] Caillette, Fabrice, Aphrodite Galata, and Toby Howard. "Real-time 3-D human body tracking using learnt models of behaviour." Computer Vision and Image Understanding 109.2 (2008): 112-125.

[17] Tong, Jing, et al. "Scanning 3d full human bodies using kinects." Visualization and Computer Graphics, IEEE Transactions on 18.4 (2012): 643-650.

[18] Chanjira Sinthanayothin, Nonlapas Wongwaen, Wisarut Bholsithi. Skeleton Tracking using Kinect Sensor \& Displaying in 3D Virtual Scene. International Journal of Advancements in Computing Technology. IJACT: International Journal of Advancements in Computing Technology, Vol. 4, No. 11, pp. 213 - 223, 2012.

[19] Karina Hadad de Souza, Rosilane Ribeiro da Mota. "Motion Capture by Kinect." SBC - Proceedings of SBGames, XI SBGames - Brasília - DF - Brazil, November 2nd - 4th, 2012.

[20] Zhang, Quanshi, et al. "Unsupervised skeleton extraction and motion capture from 3D deformable matching." Neurocomputing 100 (2013): 170-182.

[21] Shum, Hubert, and Edmond SL Ho. "Real-time physical modelling of character movements with microsoft kinect." Proceedings of the 18th ACM symposium on Virtual reality software and technology. ACM, 2012.

[22] Ilya Baran and Jovan Popovi'c. Automatic rigging and animation of 3d characters. In ACM SIGGRAPH 2007 papers, SIGGRAPH '07, New York, NY, USA, 2007. ACM.

[23] PrimeSense Ltd., Willow Garage, Side-Kick Ltd., ASUS Inc., AppSide Ltd. OpenNITM: Introducing OpenNI, http://www.openni.org/, 2010.

[24] Microsoft Inc. Kinect for Windows: Develop What's Next, http://www.microsoft.com/enus/kinectforwindows/develop/, 2012.

[25] The OpenKinect Community. OpenKinect (libfreenect), http://openkinect.org/wiki/Main_Page, 2011.

[26] Code Laboratories Inc. CL NUI Platform - Kinect Preview, http://codelaboratories.com/nui/, 2010.

[27] WIN\&I Team; Evoluce AG., INCREON GmbH. Evoluce SDK, http://www.evoluce.com/_win-andi/en/software/overview/index.php?we_objectID=55, 2011.

[28] Delicode Ltd., NI Mate. http://www.ni-mate.com/ni-mate-v1-18-released/, 2013.

[29] MakeHuman. http://www.makehuman.org/ 